EM

QUESTÃO

V.13 N. $01 \bullet 2020$

pág. 39-53

\title{
PAISAGEM E PERCEPÇÃO: IDENTIDADE E SIMBOLISMO NO MUNICÍPIO DE PASSA QUATRO - MG ${ }^{1}$
}

\section{PAISAJE Y PERCEPCIÓN: IDENTIDAD Y SIMBOLISMO EN EL MUNICIPIO DE PASSA QUATRO - MG}

\author{
Felipe da Silva VIEIRA ${ }^{2}$ \\ Flamarion Dutra ALVES ${ }^{3}$
}

\begin{abstract}
Resumo: O presente trabalho tem como objetivo central a investigação da paisagem natural e cultural do município de Passa Quatro-MG por meio da análise da percepção e das experiências da população que ali reside. Adotou-se o método fenomenológico como caminho para a realização da pesquisa, com o intuito de entender o sentido de lugar e as características simbólicas e identitárias no município. Buscou-se compreender o sentimento dos moradores, através de entrevistas semiestruturadas e técnica fotográfica. Como também, almejou-se identificar os lugares de topofilia, as características e marcas relevantes da paisagem, com a intenção de valorizartais aspectos e entender como podem ser eficientes para transformação, preservação e planejamento do município.
\end{abstract}

Palavras-chave: Lugar, Topofilia, Fenomenologia.

Resumen: El presente trabajo tiene como objetivo central la investigación del paisaje natural y cultural del municipio de Passa Quatro-MG por medio del análisis de la percepción y de las experiencias de la población que allí reside. Se adoptó el método fenomenológico como camino para la realización de la investigación, con el intuito de entender el sentido de lugar y las características simbólicas e identitarias en el municipio. Se buscó comprender el sentimiento de los habitantes, a través de entrevistas semiestructuradas y técnica fotográfica. Como tambien, se anheló identificar los lugares de topofilia, las características y marcas relevantes del paisaje, con la intención de valorar tales aspectos y entender cómo pueden ser eficientes para la transformación, preservación y planificación del municipio.

Palabras clave: Lugar, Topofilia, Fenomenología.

\section{Introdução}

Este artigo apresenta reflexões acerca da geografia humanística e cultural, com ênfase no objeto de estudo: paisagem natural e cultural de Passa Quatro-MG. O município localiza-se no sul do estado de Minas Gerais (Figura 1). Além de analisar a paisagem, objetivou-se aqui compreender o sentido do lugar, as características simbólicas e identitárias do município e como tais características podem ser importantes para o turismo e planejamento municipal. Ademais, buscou-se realizar um resgate de informações históricas com os moradores e órgãos municipais, a

\footnotetext{
${ }_{1}^{1}$ Pesquisa desenvolvida na Iniciação Científica PIBIC/CNPq - UNIFAL-MG 2017-2018.

${ }^{2}$ Graduação - Bacharelado em Geografia. Mestrando do PPGEO UNIFAL-MG. Grupo de Estudos Regionais e Socioespaciais - GERES - UNIFAL-MG. E-mail: felipevieeira95@gmail.com

${ }^{3}$ Professor Associado do Programa de Pós-Graduação em Geografia da UNIFAL-MG e UFSJ. E-mail: dutrasm@yahoo.com.br
} 
EM

QUESTÃO

V. $13 \downarrow N .01 \downarrow 2020$

pág. 39-53

fim de entender e analisar as transformações ocorridas na paisagem e, portanto, no espaço ao longo do tempo.

Figura 1: Mapa de localização do município de Passa Quatro-MG.

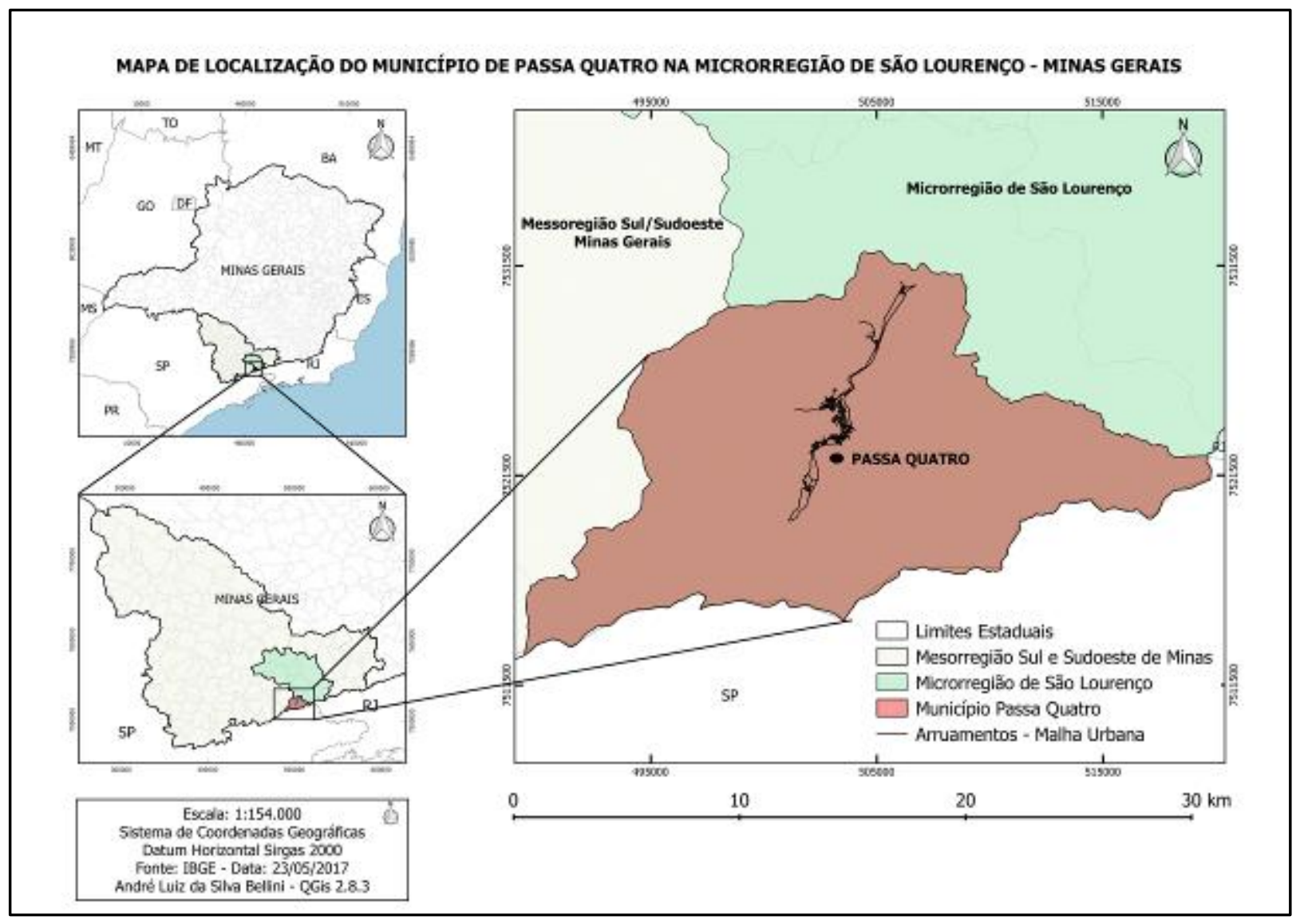

Situado na Serra da Mantiqueira o município possui em sua paisagem marcas naturais expressivas, com montanhas que se aproximam dos 3 mil metros de altitude, nascentes e cursos de água importantes para a região. Dentre as montanhas, destaca-se o complexo montanhoso da Serra Fina (Figura 2), que compreende picos como a Pedra da Mina, com 2.798 metros de altitude, sendo o quarto mais alto do país, o Pico dos Três Estados, com 2.656 metros de altitude e o Pico do Capim Amarelo, com 2.491 metros de altitude. Junto de sua localização, próxima às metrópoles de São Paulo e Rio de Janeiro, as características ambientais da paisagem estimulam a atração de turistas que buscam tranquilidade e contato com a natureza, também incentivam a realização de atividades e eventos esportivos, como o montanhismo, mountain bike e o trail running. 
Figura 2: Conjunto de Montanhas Serra Fina, município de Passa Quatro - MG.

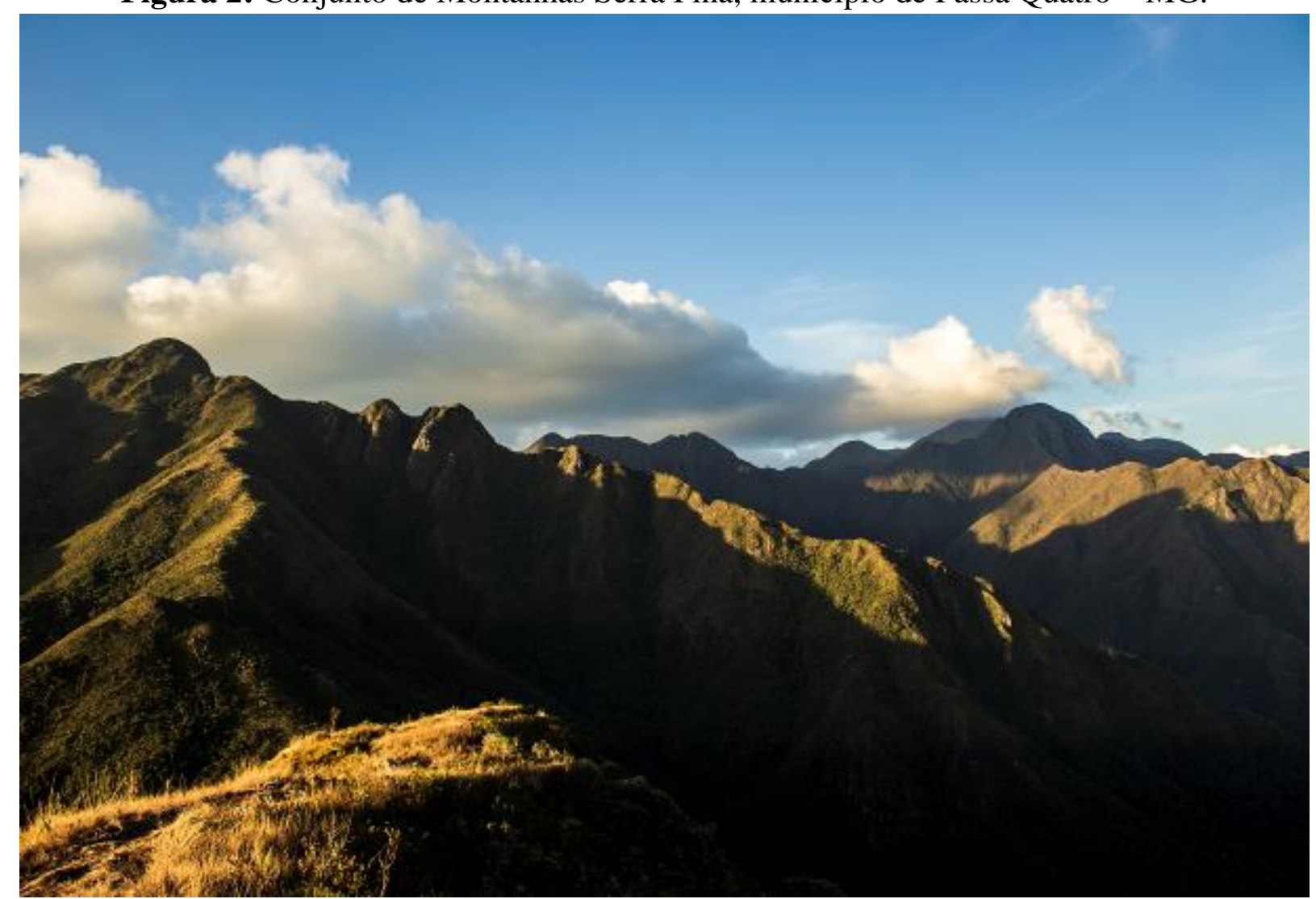

Fonte: Autor, 2018

A paisagem cultural é outra marca importante para Passa Quatro, pois há no município significativa presença de músicos, artistas plásticos, fotógrafos e artesãos. A existência destes artistas faz com que, através da arte, a ligação da população com a paisagem e o lugar seja manifestada, relacionando-se também diretamente com o potencial turístico e influenciando na produção do espaço e economia local. A paisagem cultural ainda abrange construções antigas e históricas que representam a formação e identidade do município, como a estação ferroviária, que detém o "Trem da Serra da Mantiqueira". A estação é operada pela Associação Brasileira de Preservação Ferroviária (ABPF), que se constitui em uma associação que visa a perpetuação e divulgação histórica das ferrovias do Brasil. Em alguns dias da semana a estação oferece um trajeto de trem, este trajeto pode ser realizado através do pagamento de uma taxa cobrada para a operação do serviço. O roteiro vai até o túnel existente na serra, este túnel é o marco divisório entre o estado de Minas Gerais e o estado de São Paulo.

Segundo último censo do IBGE (realizado em 2010), a população de Passa Quatro era de 15.582 habitantes, dentre estes 76,92\% são residentes do espaço urbano e 23,08\% residem no espaço rural. A economia predominante do município está ligada ao setor de serviços. O PIB total da cidade em 2014 era de 266,943 bilhões de reais, nos quais 37,34\% estão ligados ao setor de serviços, 22,2\% ligados a indústria, 20,56\% destina-se a agropecuária e 19,8\% relacionados à administração pública (IBGE, 2017).

Diante das potencialidades da paisagem, foi aguçada a curiosidade de compreender a ligação da população que está constantemente em contato com os aspectos anteriormente citados. 
EM

QUESTÃO

V.13 N. $01 \bullet 2020$

pág. 39-53

Como caminho para a realizaçãodo estudo foi adotado o método fenomenológico, utilizado através da pesquisa empírico-geográfica. De acordo com Holanda (2006, p. 370-371) "a pesquisa 'empírico-fenomenológica' envolve um retorno à experiência para obter descrições compreensivas que darão a base para uma análise estrutural reflexiva criando um retrato da essência da experiência". Portanto, trata-se de uma pesquisa qualitativa, que buscou nas experiências e vivências da população, obter uma melhor compreensão do objeto de estudo.

\section{Procedimentos metodológicos}

Para a realização da pesquisa primeiramente foram efetuadas as revisões bibliográficas de autores que trabalham a geografia humanística e cultural, buscando aprofundar conceitos e temas aqui trabalhados, como: paisagem, lugar, cultura, identidade e percepção. Concomitantemente, foi realizada uma pesquisa documental junto a Biblioteca Municipal e Casa da Cultura de Passa Quatro, onde buscou-se em recortes de jornais antigos - desde a década de 1950 -,livrose revistas, informações pretéritas que pudessem ser relacionadas com possíveis aspectos da paisagem.

Posteriormente, houve a elaboração e aplicação das entrevistas. Buscou-se na análise da revisão bibliográfica elaborar um roteiro de entrevista que envolvesse os objetivos propostos. Após análise e elaboração do roteiro, aconteceu o trabalho de campo na área de estudo.No trabalho de campo, foram realizadas entrevistas com moradores nativos(que nasceram em Passa Quatro) e moradores não-nativos (que não nasceram no município, mas mudaram-se para lá). As entrevistas foram estratificadas em 3 faixas etárias: de 15 a 25, 25 a 55 e acima de 55 anos, sendo realizadas 3 entrevistas em cada segmento. Tal estratificação ocorreu com o intuito de identificar as diferentes percepções existentes ao longo do tempo, a história e o sentimento de identidade pelo lugar das distintas gerações que ali se encontram - levando em consideração fatores estritamente qualitativos. Esse método segue o pensamento de Tuan (1985). As entrevistas foram realizadas no decorrer do mês de maio de 2018.

Realizada a aplicação das entrevistas, o trabalho de campo continuou com a produção de imagens fotográficas. Gomes (2013) destaca a utilização da imagem através do ponto de vista, composição e exposição. O ponto de vista está relacionado com o que o observador está observando e o que está sendo observado, é um dispositivo espacial. Composição refere-se à junção organizada de diversos elementos, a paisagem é uma composição e a análise da composição é uma forma de compreender a espacialidade e o lugar dos elementos que a constituem. A exposição é uma questão de posição, onde se mostra o que não se deve exibir e o que precisa ser exibido. Nesse sentido, a utilização de registros fotográficos tem a intenção não só de mostrar a realidade, mas também de compreender a totalidade. A imagem vai remeter a descrição de topofilia dos entrevistados, materializar o sentimento e as características daquela paisagem.

Por fim, após o levantamento dos dados realizado nas etapas anteriores. Foram feitas análises das informações coletadas pela pesquisa documental e pelas entrevistas realizadas com a população, elencando os lugares topofílicos e classificando os que possuem potencial turístico.

\section{Geografia Humanística e Cultural}

O geógrafo ao optar por pensar e investigar a geografia através do viés fenomenológico possui em sua trajetória não só um, mas diversos mundos. Segundo Lowenthal (1985, p. 112) "a 
EM

QUESTÃO

V.13 N. $01 \bullet 2020$

pág. 39-53

visão do mundo que os geógrafos constroem deve ser criada a cada nova geração, não somente porque a realidade muda, mas também porque as preocupações humanas variam". Portanto, as análises das transformações ocorridas no espaço, realizadas de forma geral, dão lugar a valorização das particularidades e das vivências dos atores que modificam paisagens, vivenciam lugares e, consequentemente, acabam por produzir e modificar o espaço.

De acordo com Yi-Fu Tuan (1985) o geógrafo humanista possui encargo de entender como um mero espaço se torna um lugar humano e para isso é necessário obter e analisar interesses distintamente humanísticos, como a característica da experiência, a intensidade da ligação emocional com os objetos físicos e o papel dos conceitos e símbolos que influenciam a identidade dos sujeitos para com o lugar. Holzer (1997, p. 78) destaca que a intenção da fenomenologia é "reaproximar as ciências de nossas vidas, ações e projetos, a partir das experiências ante-predicativas (anteriores aos conceitos e aos juízos), ou seja, relativas à percepção do mundo e de seus objetos enquanto fundamentos dos conceitos". Segundo Rocha (2002-2003, p. 68), “a fenomenologia veio para mostrar que o ser humano vê o mundo e seus fenômenos de acordo com sua cultura, meio ambiente, formação educacional, estado emocional, entre outros fatores que formam seu entorno e seu interior".

A fenomenologia, unida à geografia, proporciona ao geógrafo uma visão apurada da percepção dos sujeitos. Para Buttimer (1985, p. 166) "o geógrafo humanístico, afinado com as vozes do cientista e do filósofo, não pode dar-se ao luxo de ignorar qualquer coisa que possa lançar luz nas complexidades do relacionamento do homem com a terra". Deste modo, a pesquisa fenomenológica acaba por privilegiar valores qualitativos.Em uma pesquisa qualitativa, 0 equilíbrio e respeito entre o que se quer pesquisar e o sujeito pesquisado se constitui em um elemento fundamental, já que o conhecimento será obtido no acordo entre ambas as partes. No mesmo sentido, uma pesquisa efetiva relacionada à geografia humanística/cultural, não necessita de um padrão ou sistema lógico, pois a investigação do saber humano pode percorrer diversos caminhos. Chizzotti (2008), nos lembra que:

As pesquisas qualitativas, [...] não têm um padrão único porque admitem que a realidade é fluente e contraditória e os processos de investigação dependem também do pesquisador - sua concepção, seus valores, seus objetivos. Para este, a epistemologia significa os fundamentos do conhecimento que dão sustentação à investigação de um problema (2008, p. 26).

A ligação sentimental do ser humano com o meio físico e sua reprodução como cultura é fator importante no desenvolvimento da pesquisa humanística e qualitativa, considerando que, através do sentimento, podemos observar as diferentes experiências que refletem a cultura de pessoas em determinados lugares e entender o significado existente por trás das formas e símbolos. Buttimer (1985, p. 170) diz que "a fenomenologia poderia ser definida como um modo filosófico de reflexão a respeito da experiência consciente e uma tentativa para explicar isso em termos de significado e significância". Como base para o entendimento geográfico e fenomenológico do município de Passa Quatro - MG, foram analisados conceitos utilizados na geografia humanística/cultural. 
EM

QUESTÃO

V.13 N. $01 \downarrow 2020$

pág. 39-53

\section{Conceitos}

Para o geógrafo que escolhe trabalhar com o viés humanístico/cultural é fundamental ter delimitado em mente seus próprios valores e experiências, visto que o conhecimento relacionado ao sujeito deverá ser interpretado e, posteriormente transmitido. Nesse sentido, como auxílio para interpretações e levantamentos ideológicos, analisou-se autores que tratam desta vertente da geografia e utilizam conceitos como: paisagem, lugar, cultura, identidade e percepção.

De acordo com Schier (2003, p. 81) "a paisagem é a realização e materialização de ideias dentro de determinados sistemas de significação. Assim, ela é humanizada não apenas pela ação humana, mas igualmente pelo pensar". Segundo Luchiari (2001) a geografia cultural vê a paisagem como expressão material do significado que a sociedade oferece ao meio,relacionando-se com a cultura. Rosendahl (2012) ressalta que "o geógrafo, ao descrever a paisagem, exerce suas observações na busca de decodificar seus elementos simbólicos e continuadamente tirando conclusões e estabelecendo relações com os materiais visíveis na paisagem". Para Cosgrove (2012, p. 228) "todas as paisagens possuem significados simbólicos porque são o produto da apropriação e da transformação do meio ambiente pelo homem”. Portanto, o meio físico não determina a ação humana, mas sim estimula os sentidos para a criação de símbolos, produção e reprodução cultural. A geografia humanística/cultural busca a análise e apreensão da materialidade e imaterialidade existente na cultura e, consequentemente, na paisagem.

Segundo Name (2010) a cultura é entendida como trabalho, a ação do homem na natureza, que forma a produção, e também como consciência, a junção de ideias, valores, crenças e ordem moral. Cosgrove (2012, p. 225) diz que "a cultura não é algo que funciona através dos seres humanos; pelo contrário, tem de ser constantemente reproduzida por eles em suas ações, muitas das quais são ações reflexivas, rotineiras da vida cotidiana". O ser humano representa e transforma paisagens de acordo com suas necessidades e também a partir de suas experiências, esse tipo de ação carrega valores históricos e simbólicos, que podem atuar e estabelecer o sentido de como uma comunidade ou lugar se transforma e se mantém ao longo do tempo.Em relação ao conceito de lugar, Tuan (1983, p. 14) diz que "é uma classe especial de objeto. É uma concreção de valor, embora não seja uma coisa valiosa, que possa ser facilmente manipulada ou levada de um lado para o outro; é um objeto no qual se pode morar". Para Relph (2014, p. 24) "a partir da perspectiva da experiência cotidiana, lugar é muitas vezes entendido como onde se tem nossas raízes, o que sugere uma profunda associação e pertencimento, mas também imobilidade". Para Oliveira (2014) não importa se o lugar é construído ou natural, a ligação e o consequente significado atribuído acontecem quando este é percebido de maneira mais íntima ou profunda. Tuan (1983) classifica lugares íntimos como transitórios e pessoais, eles podem ficar na memória e quando são lembrados evocam uma intensa satisfação. Sentir um lugar leva um bom tempo, acontece através de experiências, através de dias ou anos. A experiência está relacionada com a possibilidade de aprender com a própria vivência, ela fica guardada no mais profundo do nosso ser.

Através das vivências o ser humano pode criar sentimentos relacionados a um determinado lugar. Tais sentimentos ou sensações podem ser classificados como sendo topofílicos ou topofóbicos. Tuan (2012, p. 19) diz que "topofilia é o elo afetivo entre a pessoa e o lugar ou ambiente físico. Difuso como conceito, vívido e concreto como experiência pessoal". A topofobia é o contrário da topofilia, remetendo ao sentimento de medo ou aversão. Tais reações vão acontecer no cotidiano, através das experiências e de como os sujeitos percebem os lugares e as paisagens. Para Tuan (2012): 
EM

Percepção é tanto a resposta dos sentidos aos estímulos externos como a atividade proposital, na qual certos fenômenos são claramente registrados, enquanto outros retrocedem para a sombra ou são bloqueados. Muito do que percebemos tem valor para nós, para a sobrevivência biológica, e para propiciar algumas satisfações que estão enraizadas na cultura (2012, p. 18).

Segundo Claval (1999) o que as pessoas recebem do mundo que as circunda, o que as pessoas experimentam, é devido a um espaço específico e à marca de cada época, o indivíduo não pode ter experiências pessoais, conhecer e se apropriar de novos ambientes, a não ser no local em que ele possui um cotidiano, com isso, ele se enraíza e pode construir um sentimento de identidade. Haesbaert (1999) argumenta que a identidade não é única, mas diversa. A definição de identidade se dá por intermédio de outras identidades e suas características demonstram-se através das condições espaço-temporais em que um grupo se localiza.

Visando trazer subsídios para o planejamento municipal, valoração da paisagem, utilização dos lugares topofílicos para o turismo e para a própria comunidade, a revisão bibliográfica, bem como as pesquisas realizadas nos órgãos municipais, tornaram possível a aplicação da pesquisa. Deste modo, este artigo baseou-se na geografia humanística/cultural, procurando através da investigação geográfica e empírico-fenomenológica, o suporte para o entendimento da paisagem e da ligação que os moradores de Passa Quatro - nativos ou não-nativos - possuem com o lugar.

\section{A paisagem e a população em Passa Quatro}

A maioria dos moradores não-nativos, quando questionados sobre o porquê de teremmudadode cidade, afirmaram que decidiram mudar para fugir do alto índice de criminalidade, considerando Passa Quatro um lugar seguro para viver. Além disso, ressaltaram o fato de que a cidade não é tão poluída e possui como atrativos aspectos naturais preservados, que influenciam na qualidade de vida do local. No que se refere ao cotidiano na cidade, foi observado - na maioria dos entrevistados - o contato com a paisagem. Muitos disseram que se sentem bem ao realizar observações e em manter um cotidiano tranquilo. $\mathrm{O}$ entrevistado 3 ressalta:

Passa Quatro tem uma das belezas mais incríveis, eu já fui pra bastante lugares e Passa Quatro tem uma coisa bucólica, uma coisa mais intimista. Que as pessoas... Você olha e as pessoas se conhecem e isso é incrível, uma cidade pequena que todo mundo se conhece,tem a magia disso e tem o lado oposto também,mas as paisagens de Passa Quatro assim, pra mim são encantadoras. Eu acho que foi um dos pontos pra eu poder vir pra cá, porque o lugar é acolhedor, lindo. (Entrevistado 3, não-nativo).

Através deste relato, é possível perceber que as belezas e qualidades naturais da paisagem foram fatores influentes para a mudança e permanência do entrevistado no município. Outro ponto importante da fala é o destaque para o lugar, definido como acolhedor. Nesse sentido, foi possível ver neste e também em outros entrevistados não-nativos uma busca por segurança ininterrupta e tranquilidade, fato que está atrelado a definição do conceito de lugar. De acordo com Oliveira (2017, p. 90) "um espaço se torna lugar com a experiência contínua e cotidiana, tanto em nível do indivíduo quanto do grupo. Por isso, o lar, a casa, constitui o centro mais profundo da existência, do 
EM

\section{QUESTÃO}

V.13 N. $01 \bullet 2020$

pág. 39-53

viver; é o significado essencial do ser humano". Estabelecer um convívio e experiências no espaçotorna-se, portanto, a consumação do lugar.O lugar se transforma para o indivíduo através da relação entre o espaço e suas sensações, sendo elas boas ou ruins.

Importante ressaltar que durante as entrevistas não só os espaços rurais foram destacados como importantes e influentes, os entrevistados também ressaltaram as marcas culturais da paisagem urbana, como: restaurantes, praças e prédios antigos. Nesse sentido, constatou-se que a paisagem de alguns bairros do espaço urbano - que ainda preservam algumas características rurais - influencia a presença de algunsmoradores. A entrevistada não-nativa 1, diz que escolheu mudar para Passa Quatro após a aposentadoria do marido, já que eles buscavam um lugar mais sossegado para morar. Sua fala continua no sentido de descrição do bairro Santa Terezinha (Figura 3), onde atualmente residem:

Aqui o bairro eu gosto porque a paisagem, por exemplo, me faz lembrar a minha infância, porque onde eu morei era mais ou menos assim, na época. Porque hoje já não é mais, né. Hoje já não é mais (em relação à paisagem da infância). Eu me sinto muito bem aqui, por causa dessas paisagens, do ambiente. (Entrevistada 1, não-nativa).

Percebe-se através deste relato uma ligação da entrevistada com o passado. A paisagem do bairro Santa Terezinha a faz lembrar seu passado, ela ainda destaca que se sente bem morandoneste bairro.

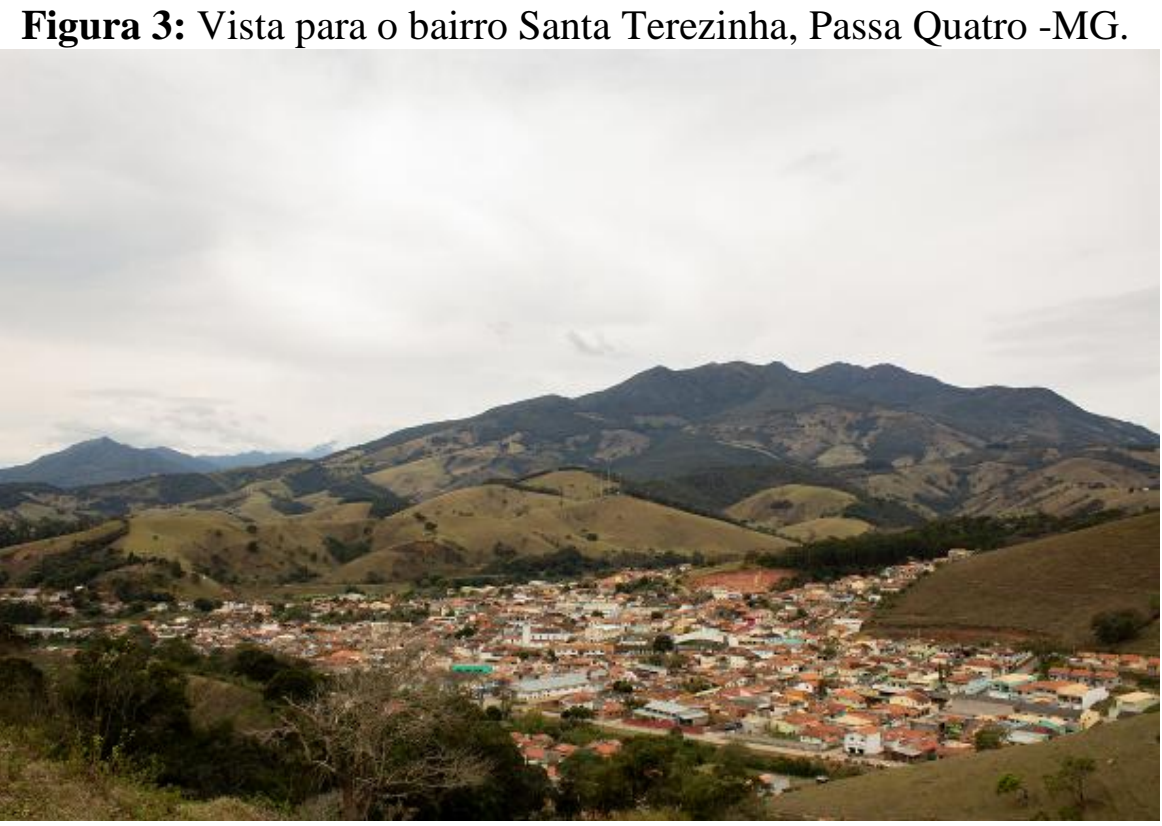

Fonte: Autor, 2018

Como a entrevistada mesmo afirmaa paisagem de sua infância já não é mais a mesma, isso se dá por conta das transformações ocorridas no espaço ao longo do tempo, transformações estas que são refletidas na própria paisagem. Segundo Corrêa (2012, p. 36) "a paisagem do presente pode apagar práticas e relações sociais do passado por meio de profundas transformações na paisagem do passado, expressão fenomênica daquelas práticas e relações". Neste caso específico, é 
EM

QUESTÃO

V.13 N. $01 \bullet 2020$

pág. 39-53

visível que a entrevistada compreende as transformações materiais da paisagem de sua infância. Por outro lado, as lembranças da paisagem ainda estão presentes em sua memória, podendo ser um fator que influenciou sua mudança para Passa Quatro, já que a paisagem do bairro Santa Terezinha atrai semelhanças e lembranças dês eu passado.

É importante ressaltar também a condição socioeconômica dos entrevistados não-nativos. A maioria das pessoas que foram entrevistadas são aposentadas ou membros de família de aposentados, que já possuem certa estabilidade financeira. Deste modo, estabelecer um cotidiano e se manter em um lugar é certamente mais fácil.

Quanto aos moradores nativos, pôde-se observar nos resultados das entrevistas uma maior participação no que diz respeito à análise da perpetuação e transformação da paisagem de Passa Quatro ao longo do tempo. Como as entrevistas foram estratificadas por faixas etárias as respostas variaram de acordo com a estratificação, sendo visível que os moradores antigos, que já vivem e experienciam o lugar há mais tempo, possuem maior conhecimento sobre a trajetória do município e deste modo, contribuíram com um maior grau de informação.

Os moradores antigos destacaram mudanças culturais e naturais na paisagem, reforçando que em outros tempos existiam maior número de festividades, como as festas juninas escolares e eventos musicais. Além disso, ressaltaram que o município possuía maior preservação ambiental. A entrevistada 2 salientou:

Ah, da época de quando eu era criança pra agora mudou muito.Tinha muito mais árvores e mudou muita coisa. E eu acho que houve assim, uma certa decadência mesmo, era bem mais arborizado, mais jardinado, tinha muito mais jardinagem na cidade. Você olhava para os morros ao redor era tudo cheio, araucária mesmo, tinha muito mais araucária do que tem hoje, né. E a água, o rio, a gente descia no rio de "bóia", imagina hoje. Hoje é um filete de água... (Entrevistada 2, nativa).

Neste relato é possível ter uma ideia do que foi a transformação da paisagem de Passa Quatro ao longo do tempo. A entrevistada afirma - através de sua experiência e percepção - que antigamente o município era mais preservado em relação a questão ambiental. Além disso, a fala evidencia uma prática cultural que antes era comum e possível de ser realizada entre os moradores, que é a descida do rio através de "bóias". Justamente por conta da diminuição do nível de água dos rios, fato que foi também destacado pela entrevistada, esta prática não é mais comum nos dias de hoje.

Já os moradores mais novos colocaram a qualidade de vida, o conforto e a ligação com o lugar como fatores que os ajudam a permanecer no município. Ao mesmo tempo, sentiram-se incomodados com as poucas oportunidades de crescer financeiramente e com a falta de acontecimentos e manutenção de eventos culturais diversos. O entrevistado 6 ressaltou:

Passa Quatro já teve nos anos 60, nos anos 70, tinha o festival da canção, que era um festival que na região aqui do sul de Minas, era bem conhecido, aí por falta de organização, acabou. A gente tem vários movimentos culturais, musicais, que aqui em Passa Quatro aconteceram por um tempo. Passou, um tempo por falta de mais vontade e esforço, patrocínio, tudo... Por exemplo, o Bazar Autoral, que a gente organizou, foi um festival de música que era só música autoral, só composição, não podia tocarcover. Só que aí a gente acabou aos poucos perdendo o gás de fazer, de organizar, e ficamos aqui sem, digamos assim, sem tesão em fazer a parada, que acabou tanto por falta de vontade dos organizadores, quanto 
EM

também por falta de patrocínio, que era muito desgastante. (Entrevistado 6, nativo).

Por meio desta fala fica evidente a questão da falta de investimento e organização mediante a manutenção de eventos culturais no município. Muitos festivais já passaram ou foram criados em Passa Quatro, todavia, poucos se mantiveram até hoje.

É possível destacar a permanência de eventos como a Exposição Agropecuária e Artesanal, o próprio Carnaval que acontece todo ano, porém, de acordo com os entrevistados, ainda falta no calendário cultural do município maior número de eventos que se perpetuem. Por outro lado, há também a existência de alguns outros eventos que foram criados nos últimos anos e que vêm se mantendo. Alguns entrevistados destacaram eventos como o "Passa Quatro canta" e o "Passa Quatro Gastronomia", que ocorrem todo ano, o primeiro geralmente no mês de abril e o segundo no mês de maio ou junho.

\section{Lugares topofílicos}

A aplicação das entrevistas e seu posterior estudo possibilitou elencar os lugares que os entrevistados se sentem confortáveis, com um maior elo afetivo. Estes são os lugares topofílicos, que através das informações coletadas foram salvaguardados por meio de fotografias.

A produção fotográfica visa compreender a materialização do sentimento e a percepção da população. Além disso, as fotografias possuem a importância de salvaguardar os lugares ressaltados, para que os mesmos não sejam esquecidos pelo poder público e possam ser utilizados no que diz respeito ao planejamento municipal.Dentre os lugares considerados topofílicos, destacam-se: Ingazeiro, Instituto do Pinho/Ibama (atualmente ICMBio) e Mata dos Alemães (Figuras 4, 5 e 6, respectivamente).

Figura 4: Ingazeiro, município de Passa Quatro-MG.

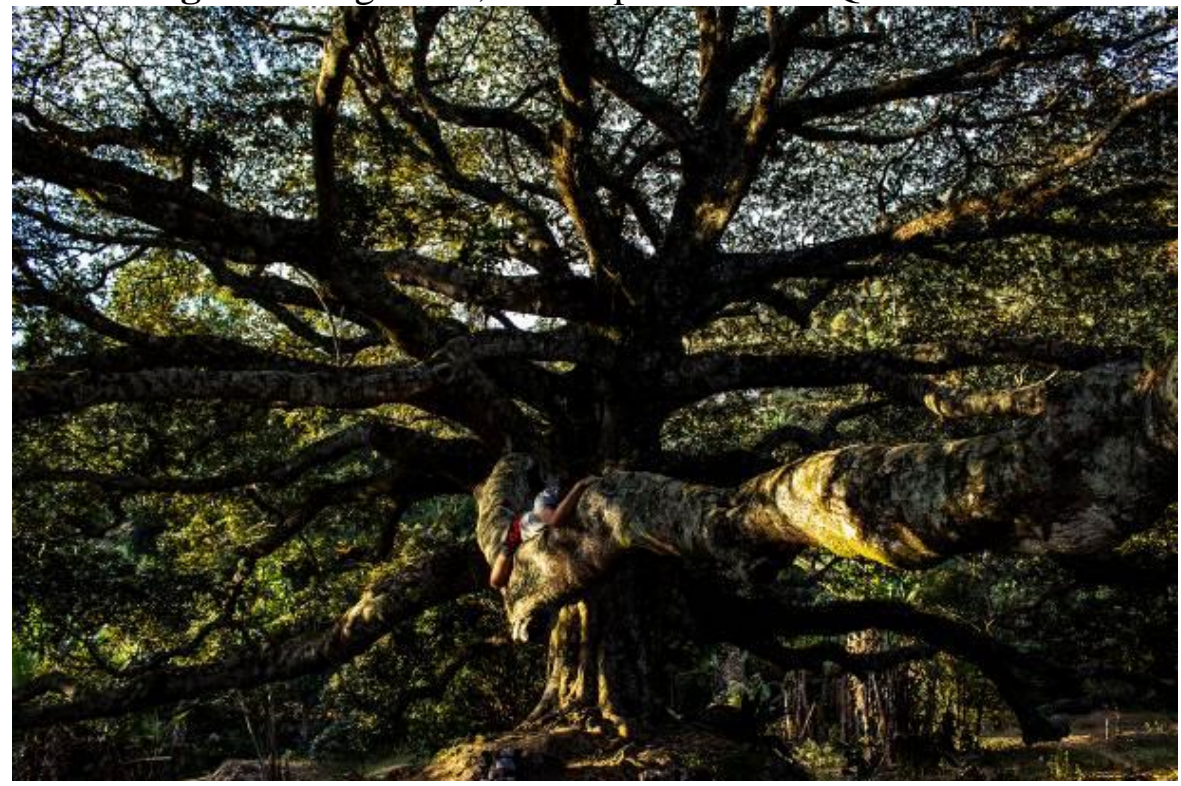

Fonte: Autor, 2018. 
EM

O Ingazeiro é uma árvore centenária que está localizada no bairro Quilombo, bairro rural do município.Ao relatar sobre o que o lugar significa, a entrevistada 2 ressalta:

É um lugar maravilhoso, tem uma energia, uma coisa... É fantástico o Ingazeiro.Um lugar que dá pra todo mundo ir e tal, né. Então assim, as vezes eu questiono muito. Para os próprios moradores não tem acesso a esses lugares. Não precisa ser nem todo dia, lógico, o cotidiano..., mas sei lá, de repente chegar em época de feriado e ter um circular que levasse, entendeu? Para o Ibama,que leve até, sabe?(Entrevistada 2, nativa).

Além de expressar suas sensações ao frequentar o lugar, a entrevistada toca em outra questão muito importante. Muitos moradores não possuem conhecimento ou acesso ao Ingazeiro, fato que não está atrelado apenas a este lugar, mas também a outros lugares do município. $\mathrm{O}$ Ingazeiro, assim como outros lugares do território municipal, é conhecido como ponto turístico e muitas pessoas procuram frequentarPassa Quatro com o intuito de conhecer estes lugares. Além de mostrar esse problema, ela propõe como sugestão a criação de uma linha de ônibus para que os moradores possam também usufruir destes espaços, que muitas vezes são restritos apenas aos turistas.

Outro lugar que também foi considerado como topofílico pelos entrevistados é o Ibama. Trata-se de uma Floresta Nacional (Flona), este espaço primeiramente foi coordenado pelo antigo Instituto Nacional do Pinho, depois pelo Instituto Brasileiro do Meio Ambiente e dos Recursos Naturais Renováveis (IBAMA) e atualmente é coordenada pelo Instituto Chico Mendes de Conservação da Biodiversidade(ICMBio).

Figura 5: "Ibama", atual ICMBio, município de Passa Quatro-MG.

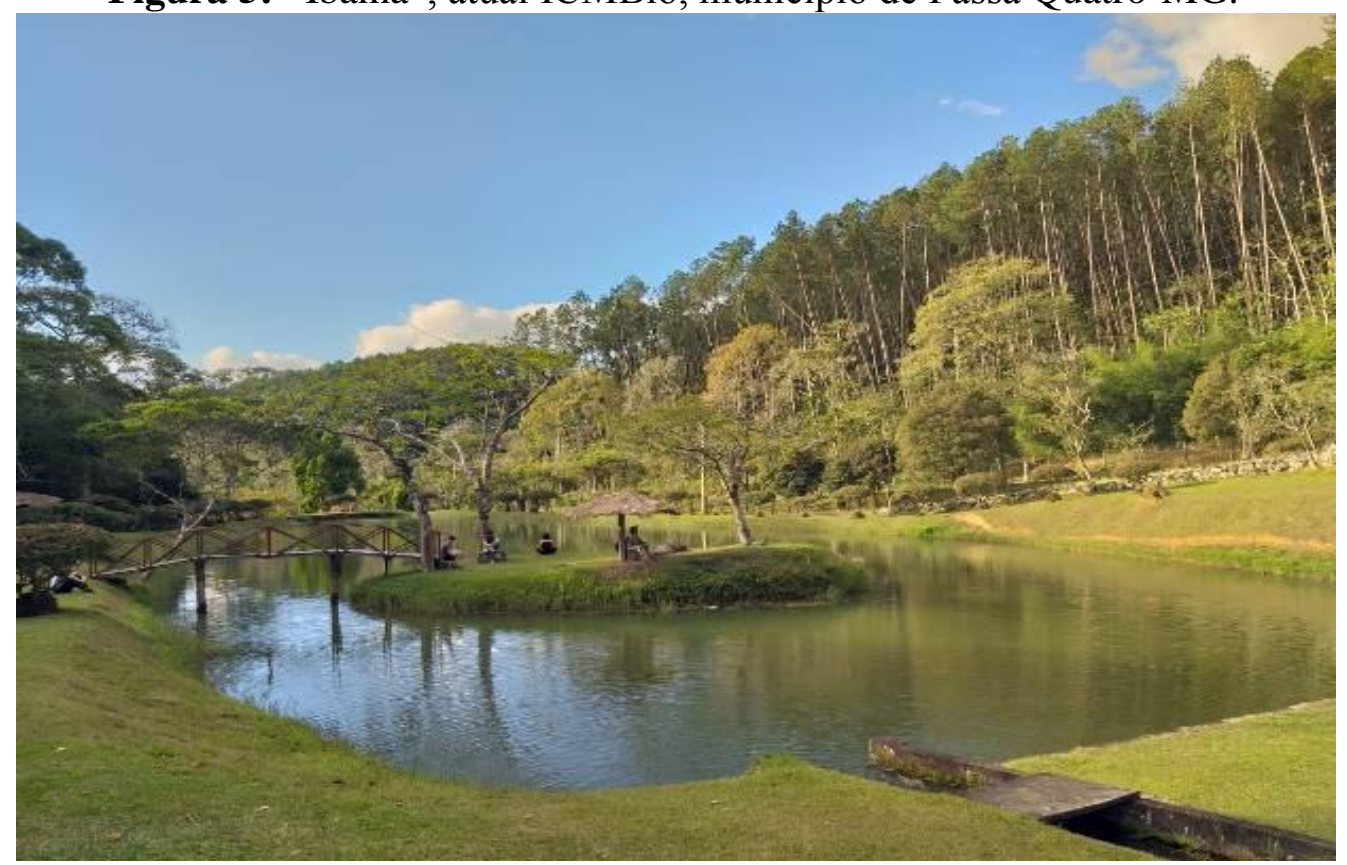

Fonte: Autor, 2018.

O fato de o lugar ter sido coordenado durante muito tempo pelo Instituto do Pinho e pelo Ibama fez com que o mesmo ficasse popularmente conhecido entre os moradores como "Pinho" e 
EM

QUESTÃO

V.13 N. $01 \bullet 2020$

pág. 39-53

"Ibama". Ao citar estes nomes pelas ruas do município, a maioria dos moradores certamente já irão saber onde é e vão possuir informações sobre o lugar.

Ao ser questionado sobre qual lugar costuma frequentar para descanso e lazer, o entrevistado 4 afirma:“ah, o Ibama em si é uma coisa bem bacana, desde a própria cachoeira que tem lá, tem o viveiro das mudas com árvores frutíferas, tudo. É muito bacana lá” (Entrevistado 4, nativo). Neste lugar é possível se banhar na cachoeira e também realizar algumas trilhas, bem como realizar outros tipos de visitações para pesquisa e lazer em geral. A entrevistada 2, declara:"pra mim, o Ibama é mais por ser de fácil acesso, né. É um lugar que todo mundo pode ir, fazer um piquenique com as crianças, dá pra ir de bicicleta, fácil, vamos dizer assim, de ir, né...”. Por estar localizado próximo a cidade e ser bem conhecida, a Floresta Nacional acaba por ser um destino frequente entre moradores e turistas.

Por último, outro lugar que também foi classificado como topofílico é a Mata dos Alemães. Este lugar está localizado em um bairro rural do município, o bairro Ferreirinha.

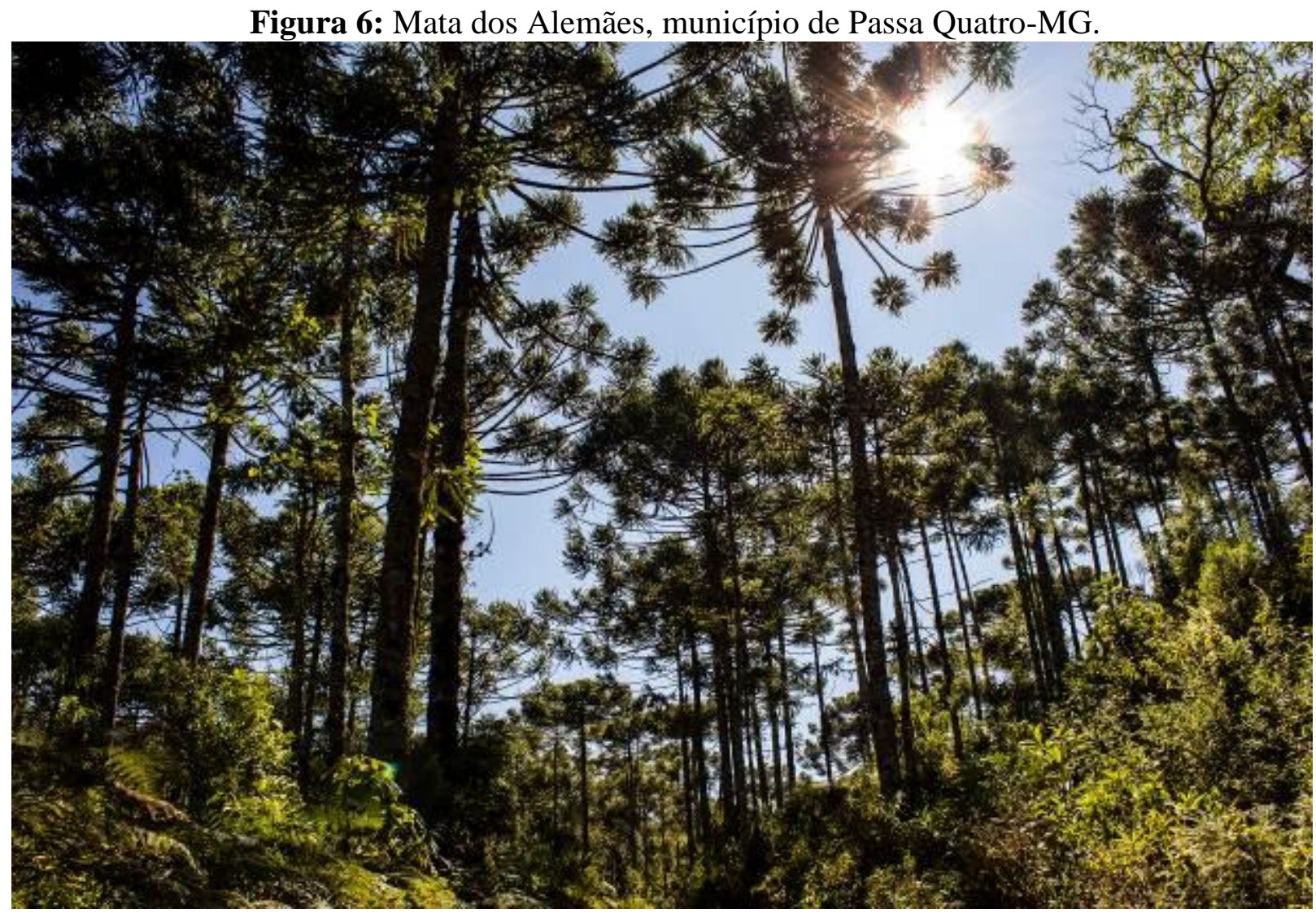

Fonte: Autor, 2018.

É um lugar que conta com uma área extensa de plantação de pinheiros, como as Araucárias. Lá também é possível identificar uma construção antiga, que remete ao tempo colonial, trata-se de uma antiga fazenda que atualmente encontra-se abandonada. Ao descrever o lugar, a entrevistada 7 afirma: 
EM

QUESTÃO

V.13 N. $01 \bullet 2020$

pág. 39-53

A Mata dos Alemães, é um lugar místico, misterioso. Quando você entra nela, é um caminho na verdade, né. Quando chega em determinado ponto da estrada, gente... A paisagem muda totalmente, você se sente na Europa, é um negócio muito louco! A estrada é fechada de matas, aqueles pinheiros enormes... por issoque chama Mata dos Alemães, sabe? E você sente a energia do lugar, é uma coisa... Não tem explicação, teria que ir lá. (Entrevistada 7, nativa).

Por meio desta fala, é possível perceber que a paisagem e a sensação de frequentar o lugar provoca na entrevistada certa sensação de fuga de sua realidade. Este lugar não é de fácil acesso para os moradores e também é pouco conhecido entre os mesmos. O fato de estar localizado em um bairro rural, que é mais afastado do perímetro urbano e está próximo da divisa com o município de Virgínia - MG, faz com que o lugar não seja muito frequentado pelos moradores da cidade e seja mais conhecido pelos moradores que vivempróximo ou dentro dos limites do bairro Ferreirinha.

De modo geral, constatou-se que a maioria dos entrevistados relacionaram topofilia com características ambientais ainda preservadas, ressaltando lugares que se encontram dentro do espaço rural. Tal fato pode estar associado com a noção de qualidade de vida, que encontra-se relacionada à preservação ambiental. Além do mais, por conta do difícil acesso aos pontos turísticos localizados nos bairros rurais, os moradores costumam frequentar na maior parte do tempo os espaços urbanos, fazendo com que os espaços rurais sejam visitados nos momentos de lazer.

\section{Considerações finais}

É evidente que desde sua criação Passa Quatro é marcada pelos aspectos naturais existentes em sua paisagem. A presença da Serra da Mantiqueira possibilita ao município montanhas e morros expressivos, bem como qualidade no que diz respeito aos recursos hídricos, destaque para as fontes hidrominerais distribuídas pelas praças da cidade, para as cachoeiras e nascentes, dentre elas a nascente do próprio Rio Verde, um importante rio para o Sul de Minas Gerais.

Com o passar do tempo a marca cultural na paisagem também se tornou relevante, como exemplo temos os casarões antigos, fazendas, manifestações artísticas e a própria estação da Maria Fumaça. No que diz respeito aos acontecimentos culturais, foi possível observar que diversos eventos não se perpetuaram, devido à falta de incentivo e infraestrutura por parte do poder público. Nesse sentido, vale reforçar a importância de incentivar e manter a paisagem cultural e natural, uma vez que tais aspectos são essenciais para o município, podem trazer benefícios para a própria população que ali reside e também atrair turistas, maximizando o crescimento econômico, junto com apreservação ambiental e cultural do município.

Com a realização da pesquisa, pôde-se perceber que, atualmente, o contato da população local com os aspectos da paisagem e do lugar é diversificado. Ao mesmo tempo em que alguns moradores mostraram conhecer e frequentar os lugares topofílicos, outros tantos não sabem da existência ou não possuem o devido acesso. Portanto, torna-se necessário pensar o planejamento de Passa Quatro visando a utilização do potencial paisagístico, a fim de que os moradores possam ter melhor acesso aos lugares e para que as atividades turísticas possam se desenvolver de maneira consciente e sustentável. 
EM

QUESTÃO

V.13 N. $01 \bullet 2020$

pág. 39-53

\section{Referências}

BUTTIMER, A. Apreendendo o dinamismo do mundo vivido. In: CRHISTOFOLETTI, A. (Org.)

Perspectivas da geografia. 2ed.São Paulo: DIFEL, 1985. p. 165-193.

CHIZZOTTI, A. Pesquisa qualitativa em ciências humanas e sociais. 2. Ed. Petrópolis, RJ: Vozes, 2008.

CLAVAL, P. A Geografia Cultural: O Estado da Arte. In: ROSENDAHL, Z; CORRÊA, R.L. (Orgs.) Manifestações da cultura no espaço. Rio de Janeiro:Ed.Uerj, 1999. p. 59- 98.

CORREA, R.L. Paisagem e geografia. In: NEGREIROS, C; LEMOS, M; ALVES, I (Orgs.) Literatura e Paisagem em diálogo. Rio de Janeiro: Edições Makunaima, 2012. p. 29-43.

COSGROVE, D. A geografia está em toda parte: cultura e simbolismo nas paisagens humanas. In: CORREAA, R.L; ROSENDAHL, Z. (Orgs.) Geografia cultural: uma antologia. v.1. Rio de Janeiro: Eduerj, 2012. p. 219-237.

GOMES, P.C.C. O lugar do olhar: Elementos para uma geografia da visibilidade. Rio de Janeiro: Bertrand Brasil, 2013.

HAESBAERT, R. Identidades Territoriais. In: ROSENDAHL, Z; CORRÊA, R.L. (Orgs.) Manifestações da cultura no espaço. Rio de Janeiro:Ed. Uerj, 1999. p. 169-188.

HOLANDA, A. Questões sobre a pesquisa qualitativa e pesquisa fenomenológica. Análise Psicológica. Lisboa. v.24, n.3, 2006. p. 363-372.

HOLZER, W. Uma discussão fenomenológica sobre os conceitos de paisagem e lugar, território e meio ambiente. Revista Território. Rio de Janeiro. n.3, 1997. p.77-85.

INSTITUTO BRASILEIRO DE GEOGRAFIA E ESTATÍSTICA. IBGE Cidades. Disponívelem:http://cidades.ibge.gov.br/xtras/perfil.php?codmun=314760\&lang. Acesso em: 30 jun. 2018.

LOWENTHAL, D. Geografia, experiência e imaginação. In: CHRISTOFOLETTI, A. (Org.) Perspectivas da geografia. 2ed.São Paulo: DIFEL, 1985. p. 103-141.

LUCHIARI, M.T. A (re)significação da paisagem no período contemporâneo. In: ROSENDAHL, Z; CORRÊA, R.L (Orgs.) Paisagem, Imaginário e Espaço. Rio de Janeiro: Ed. UERJ, 2001. p. 9-28.

NAME, L. O conceito de paisagem na geografia e sua relação com o conceito de cultura. GeoTextos. Salvador, v. 6, n. 2, 2010, p.163-186.

OLIVEIRA, L. Panorama dos estudos de geografia e percepção do meio ambiente. In: MARANDOLA, E; CAVALCANTE, T (Orgs.) Percepção do meio ambiente e geografia: 
EM

QUESTÃO

V.13 N. $01 \bullet 2020$

pág. 39-53

estudos humanistas do espaço, da paisagem e do lugar. São Paulo: Cultura Acadêmica, 2017. p. 89-109.

OLIVEIRA, L. O sentido de lugar. In: MARANDOLA, E; HOLZER, W; OLIVEIRA, L. (orgs.). Qual o espaço do lugar? São Paulo: Perspectiva, 2014. p. 3-16.

RELPH, E. Reflexões Sobre a Emergência, Aspectos e Essência de Lugar. In: MARANDOLA, E; HOLZER, W; OLIVEIRA, O. (Orgs.). Qual o espaço do lugar? São Paulo: Perspectiva, 2014. p. 17-32.

ROCHA, L.B. Fenomenologia, semiótica e geografia da percepção: alternativas para analisar o espaço geográfico. Revista da Casa da Geografia de Sobral.v.4/5, p.67-79, 2002/2003.

ROSENDAHL, Z. Paisagem simbólica como descrição da personalidade do lugar: a certidão de nascimento do Brasil. In: NEGREIROS, C; LEMOS, M; ALVES, I (Orgs.) Literatura e Paisagem em diálogo. Rio de Janeiro: Edições Makunaima, 2012. p. 45 - 56.

SCHIER, R.A. Trajetórias do conceito de paisagem na geografia. Revista RA'E GA. Curitiba, n.7, 2003, p. 79-85.

TUAN, Y.F. Espaço e Lugar: A Perspectiva da Experiência. São Paulo: DIFEL, 1983.

TUAN, Y. F. Geografia Humanística. In: CRHISTOFOLETTI, A. (Org.) Perspectivas da geografia. 2ed.São Paulo: DIFEL, 1985. p.143-164.

TUAN, Y.F. Topofilia: Um estudo da percepção, atitudes e valores do meio ambiente. Londrina: Eduel, 2012.

Artigo recebido em 21-07-2019

Artigo aceito para publicação em 10-03-2020 